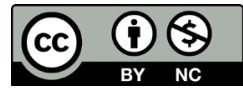

\title{
INTERPRETAÇÃO, INTEGRIDADE, IMPÉRIO DA LEI: O DIREITO COMO ROMANCE EM CADEIA
}

INTERPRETATION, INTEGRITY, AND THE RULE OF LAW: LAW AS CHAIN NOVEL WRITING

Lenio Luiz Streck

Gilberto Morbach Júnior

\section{RESUMO}

Este artigo pretende analisar a proposta teórica, articulada por Ronald Dworkin, que oferece uma explicação do fenômeno jurídico a partir da analogia com a construção literária de um romance em cadeia. Nesse sentido, por intermédio de uma revisão bibliográfica pautada sob o método fenomenológico, pretendemos abordar o ideal maior de integridade subjacente à metáfora de Dworkin e, a partir daí, investigar as possíveis contribuições dessa ideia ao direito brasileiro à luz do império da lei.

Palavras-chave: Direito como integridade. Ronald Dworkin. Império da lei.

\section{ABSTRACT}

This essay seeks to analyze Ronald Dworkin's theoretical approach and its explanation of law through the metaphor of a chain novel project. By way of a bibliographic research under the phenomenological method, we seek to explore the bigger, underlying idea of integrity supporting Dworkin's idea. From that, we argue in favor of possible contributions of the chain novel explanation to Brazilian legal practice illuminated by the rule of law. 
Keywords: Law as integrity. Ronald Dworkin. Rule of law.

\section{INTRODUÇÃO}

Ronald Dworkin é, sem dúvida, um dos mais influentes jusfilósofos da história do pensamento jurídico ocidental. Como bem define Stephen Guest (2013, pp. 11-12), Dworkin “tem sido, por muitas décadas, enormemente citado em livros e periódicos jurídicos, políticos, filosóficos e econômicos"; "importantes autores, que concordam e discordam com ele, estão certamente unidos em torno da noção de que suas ideias são de enorme significado". ${ }^{1}$

Dworkin não foi (somente) um crítico do positivismo jurídico; foi, igualmente, um grande crítico do pragmatismo jurídico (sobretudo, na versão de Richard Posner), do originalismo enquanto abordagem de interpretação constitucional (tendo seu antagonista no então juiz da Suprema Corte Antonin Scalia) e do pluralismo valorativo na ética ${ }^{2}$ (tal como personificado sobretudo por Isaiah Berlin). Naturalmente, contudo, Dworkin não foi apenas um crítico, um teórico negativo: enquanto desenvolvia suas tão amplas (e fortes) críticas, Dworkin acabou também por articular, ao longo dos anos, uma concepção original, muito própria, acerca do direito, da própria prática jurídica, da teoria política e da justiça, e, em sentido mais amplo, da própria filosofia moral - em um projeto que se apresenta como unitário e coerente.

Por trás de tudo isso, de toda sua obra, está, fundamentalmente, a noção de integridade: aquela que é, para Waldron (2019, p. 01), "uma das mais complexas, interessantes e originais concepções na filosofia jurídica". ${ }^{3}$ Esse ideal - concebido por Dworkin como a melhor interpretação, tanto descritiva quanto normativamente, acerca do direito - é muito bem explicado pelo autor a partir de uma metáfora muito familiar na literatura jurídica; tão familiar quanto subestimada ou mal compreendida (WALDRON, 2019, pp. 05-06). Trata-se da ideia de direito explicada por meio da metáfora de um romance em cadeia.

Sendo assim, considerando-se (i) a importância do autor, (ii) a relevância da metáfora do direito como um romance em cadeia para sua 
concepção teórica e (iii) a ideia de que talvez a analogia do direito como um romance em cadeia tenha sido subestimada pela doutrina ao longo dos anos, este ensaio pretende fazer justiça à ideia de integridade na obra de Dworkin e elaborar possíveis contribuições de sua proposta ao direito brasileiro, fortalecendo o ideal de império da lei.

\section{DWORKIN, O ROMANCE EM CADEIA E O IDEAL DE INTEGRIDADE}

Como dito, Jeremy Waldron sustenta que, por mais familiar que seja a analogia do direito como a prática construtiva de um romance em cadeia, ela é igualmente subestimada. Por quê? Para Waldron (2019, p. 05),

[...] os juristas têm achado atrativa essa metáfora, mas satisfazem-se em considerar sua aplicação sem dar muita atenção ao argumento subjacente. Por que o direito é como um romance em cadeia? Por que não é, antes, uma coletânea de contos de William Trevor ou Flannery O'Connor? Essa questão nunca é enfrentada por aqueles que fazem uso da analogia de Dworkin. ${ }^{4}$

Isso porque, segue Waldron (2019, p. 06), esses juristas não compreendem a verdadeira teoria: a teoria de integridade que, exatamente, oferece a sustentação para o que pode ser visto como uma simples metáfora. É necessário, então, que se aborde essa questão. Antes, contudo, é necessária uma digressão; é necessário estabelecer os pressupostos teóricos que servem de base e constituem o pensamento dworkiniano. Falar sobre um autor com responsabilidade, afinal, exige que se delimite bem aquilo sobre o que estamos falando.

\section{O INTERPRETATIVISMO DWORKINIANO, DIREITO E DEMOCRACIA}

De acordo com Dworkin, o fenômeno jurídico deve ser encarado como um fenômeno interpretativo. Em sua concepção de direito como integridade, "o raciocínio jurídico [legal reasoning] é um exercício de interpretação construtiva", de modo que o direito de uma comunidade 
"consiste na melhor justificativa que sustenta as práticas jurídicas como um todo"; consiste, pois, "na história narrativa que faz dessas práticas $o$ melhor que elas podem ser". A interpretação construtiva de uma prática, na leitura de Dworkin, é precisamente uma questão de atribuição de modo a torna-la o melhor exemplo possível da forma ou gênero ao qual se presume que ela pertence. 0 propósito da interpretação é, visto sob essa perspectiva, tornar aquilo que se interpreta o melhor que pode ser; assim, uma abordagem de interpretação construtiva sobre a prática jurídica será uma proposta interpretativa que visa a oferecer uma leitura dessa prática vista "sob sua melhor luz"5 (DWORKIN, 1986, p. vii; pp. 52, 61, 139).

Com relação a esse processo interpretativo, Dworkin delimita e divide o processo em três estágios. Primeiro, (i) um estágio "préinterpretativo", no qual se determinam as regras e padrões dentro dos quais se pode identificar o conteúdo da prática interpretada. São classificações cotidianas, os graus mínimos que permitem que algo seja inteligivelmente interpretado. (Dworkin [1986, pp. 65-66] exemplifica o estágio "pré-interpretativo" através da interpretação literária, na qual esse estágio consistiria na identificação de Moby Dick e sua distinção dos textos que correspondem a outras obras).

Depois, surge (ii) o estágio interpretativo - estágio que ilumina de forma bastante clara a concepção de interpretação construtiva em Dworkin (1986, pp. 65-66). Para o autor, o estágio interpretativo é o estágio no qual "o intérprete adota uma justificativa geral para com os principais elementos que constituem a prática identificada no estágio 'pré-interpretativo'”6 (DWORKIN, 1986, p. 65), o que consiste, basicamente, em um argumento sobre a validade da prática em questão. Essa interpretação não precisa contemplar todo aspecto, todos os elementos da prática interpretada, é verdade; deve, contudo, ainda assim, ir de encontro a elementos suficientes, elementos que pertencem ao estágio "pré-interpretativo", de modo a fazer com que o intérprete esteja, genuinamente, interpretando a prática, e não inventando uma nova.

Finalmente, então, vem o terceiro estágio; o (iii) estágio pósinterpretativo, ou "reformador". Nessa fase, o intérprete "ajusta sua percepção do que a prática 'realmente' exige de modo a melhor servir 
à justificação por ele aceita no estágio interpretativo"7 (DWORKIN, 1986, p. 66). O autor, aqui, dá o exemplo da prática da cortesia em uma sociedade - prática que permeia sua obra como um paradigma suficientemente exemplificativo de uma prática interpretativa: no estágio pós-interpretativo, um intérprete da cortesia poderia vir a pensar que um reforço consistente daquilo que melhor justifica a prática exigiria que as pessoas saudassem com seus chapéus os soldados que retornam de uma guerra; ou, ainda, que a melhor justificativa da prática exige, em verdade, uma (nova) exceção a um padrão previamente estabelecido, de modo que soldados que retornam da guerra estariam isentos de demonstrações de cortesia; ainda, o intérprete poderia chegar à noção de que a prática vista sob sua melhor luz levaria à conclusão de que toda uma regra que estipulasse a deferência a toda uma classe ou grupo de indivíduos é, em si, uma regra equivocada (DWORKIN, 1986, p. 66).

Sendo o direito uma prática interpretativa, também sua interpretação terá os três estágios. No estágio "pré-interpretativo", contudo, não se trata de identificar o que compõe a prática jurídica através de definições compartilhadas sobre definições acerca do que conta como um sistema jurídico - sob pena de a explicação ser uma explicação criterial, semântica e, por isso, contrária à ideia de um conceito interpretativo. Não é difícil identificar, coletivamente, as práticas que contam como práticas jurídicas em nossa cultura; cortes, legislaturas, agências administrativas, sabe-se tranquilamente que isso forma um sistema jurídico. Contudo, a questão sobre quais características específicas esses elementos têm características em virtude das quais elas formam um sistema jurídico - é parte do problema interpretativo (DWORKIN, 1986, p. 87).

Nesse sentido, o filósofo do direito deve começar a partir de uma identificação pré-interpretativa minimamente incontroversa sobre o caráter da prática jurídica. Como o respeito é um conceito da cortesia, as concepções sobre a prática partem desse conceito; também assim será com relação ao direito, visto que práticas da mesma natureza. Assim, Dworkin propõe que, dado que os governos têm propósitos, atingíveis também por meio do monopólio do uso da força, é legítimo dizer que o sentido mais fundamental e abstrato da prática jurídica é justificar a coerção do Estado que exsurge de decisões políticas do passado. A prática 
jurídica de uma comunidade é, nesse sentido, um esquema de direitos e responsabilidades que vai de encontro a esse padrão, e é jurídica porque relacionada a essas decisões políticas do passado. Essa é, para Dworkin, uma caracterização ("pré-interpretativa") segura porque compatível com um (bastante) amplo rol de reivindicações e argumentos que contradizem um ao outro com relação a quais direitos e responsabilidades de fato derivam dessas decisões políticas do passado e, por tal razão, permitem a coerção do Estado.

Para o direito como integridade, os limites jurídicos não oferecem apenas previsibilidade e/ou justiça procedimental, ou qualquer outra questão (meramente) instrumental; o direito é o que garante um determinado tipo de igualdade entre cidadãos que torna sua comunidade mais genuína e melhora o tipo de justificação moral que sustenta o exercício de poder político. Isso posto, então, para a concepção de law as integrity, direitos e responsabilidades derivam de decisões políticas precedentes e são, qua direitos e responsabilidades, jurídicos não apenas quando estiverem explícitos nessas decisões, mas (também) quando deriváveis "dos princípios de moralidade política e pessoal que as decisões explícitas pressupõem como suas justificativas"8 (DWORKIN, 1986, p. 96).

Nesse sentido, o direito como integridade

[...] nega que proposições jurídicas sejam as descrições factuais, de olhar retrospectivos, do convencionalismo, ou os programas instrumentais, prospectivos, do pragmatismo jurídico. [Law as integrity] insiste que reivindicações jurídicas são juízos interpretativos e, sendo assim, combinam elementos retro e prospectivos; interpretam a prática jurídica atual como uma narrativa política que se desdobra. 0 direito como integridade, então, classifica como inútil a velha questão que pergunta se os juízes descobrem ou inventam direito, e sugere que só compreendemos o raciocínio jurídico ao enxergamos em que medida eles fazem ambas as coisas e nenhuma delas $^{9}$ (DWORKIN, 1986, p. 225)

Assim, Dworkin (1986, p. 225) vai conceber que as proposições jurídicas são verdadeiras enquanto proposições jurídicas na medida em que se seguirem de princípios de justiça, equidade, e devido processo, a partir dos quais se pode estabelecer a melhor interpretação construtiva da prática jurídica da comunidade. 
Dworkin, rejeita, portanto, ao mesmo tempo, tanto a ideia de um direito absolutamente cindido das esferas da política e da moralidade quanto a ideia de que os juízes não se diferem de outros officials ${ }^{10}$ responsáveis pela tomada de decisões. É precisamente nesse sentido que, em contraste com a visão tipicamente associada ao positivismo jurídico, Dworkin compreende que, em casos difíceis - casos em que a compreensão ordinária diz não haver direito aplicável, na medida em que inexiste uma regra clara, inequívoca e (em tese) unívoca que aponte à solução —, os juízes não estão desvinculados para agir com discricionariedade; estão adstritos aos princípios de moralidade política e às decisões políticas e jurídicas precedentes (DWORKIN, 1978, pp. 14-45).

Em meio a isso, portanto, Dworkin vai estabelecer a diferença fundamental entre argumentos de política - cuja natureza é autoevidente - e argumentos de princípio, que são justamente os argumentos que fundamentam uma decisão tomada não a partir de cálculos utilitários (ou mesmo propriamente políticos per se), mas a partir de uma exigência das noções de justiça que se adequem à moralidade institucionalizada. Sendo assim, e na exata medida em que Dworkin entende que (i) direito e moralidade política não estão separados, e mais, que (ii) do juiz responsável é exigido que se aplique as convicções institucionalizadas de moralidade política, a visão dworkiniana de uma democracia liberal é algo que transcende as noções que envolvam apenas um ideal (meramente) majoritário. Direitos (individuais, políticos) funcionam como "trumps", como "trunfos" em face de argumentos que, porque baseados em (pré-) argumentos anteriores de cunho majoritário, podem muitas vezes carregar um viés político, utilitário-instrumental, intrínseco (DWORKIN, 1985, pp. 59, 68, 82; DWORKIN, 2005, pp. 01-37). Na concepção dworkiniana de democracia, os cidadãos são iguais, tratados como iguais, e tem "igual participação nos resultados", o que significaria muito mais que um voto de igual peso. A regra da maioria não tem qualquer valor por si só e em si mesma (DWORKIN, 2011, p. 348).

\section{INTEGRIDADE E IMPÉRIO DA LEI A PARTIR DO ROMANCE EM CADEIA}


Estabelecidos esses pressupostos, podemos finalmente avançar às seguintes questões: 0 que Dworkin tem em mente quando diz que o direito pode ser melhor explicado a partir da metáfora de um romance em cadeia? Qual é esse ideal de integridade que lhe serve de base fundamental?

Para Dworkin (1986, pp. 228-232), como um romance construído em cadeia, num projeto em conjunto, também o direito pode ser considerado um empreendimento coletivo entre autores que se propõem à escrita conjunta de uma única obra. Um processo desse tipo pressupõe, naturalmente, a obrigação daquele que escreve de manter coerência com os elementos que já fazem parte da obra: os elementos que lá já estavam antes de sua participação.

Assim, como os autores envolvidos no romance em cadeia - e trazendo a analogia para a esfera jurídica - os juízes são, igualmente, "autores e críticos" (DWORKIN, 1986, p. 229): decidindo os casos concretos, específicos, que a eles são apresentados, juízes contribuem para com a tradição que interpretam, adicionando a ela novos elementos; os juízes subsequentes, portanto, vão encontrar uma tradição que se renova ao mesmo tempo em que guarda coerência de princípio com o passado.

Em um romance em cadeia, "cada um dos autores", dirá Dworkin, "procura fazer um romance único a partir dos materiais que tem à mão, daquilo que acrescenta e (na medida em que pode controlar isso) daquilo que seus sucessores quiserem ou puderem adicionar." É por isso que ele deve "tentar fazer do romance o melhor que ele pode ser construído como se fosse o trabalho de um único autor" ${ }^{11}$ (DWORKIN, 1986, pp. 229-230). É isso que deve fazer o juiz: fazer do direito o melhor que ele pode ser, como se o ordenamento fosse um todo coerente, construído por um único autor; "como se os direitos e políticas promovidos e protegidos pelas instituições políticas fossem todos derivados de uma série coerente de princípios, passíveis de serem reforçados por um único agente moral"12 (MARMOR, 2019, p. 02).

Trata-se, afinal, de exigir do Estado uma atuação em torno de princípios coerentes mesmo quando haja, entre os Cidadãos, desacordos sobre o que os princípios corretos de justiça exigem (DWORKIN, 1986, p. 166). Nesse processo, o que está em jogo é o valor/sentido da própria 
prática. Ou seja, sendo o direito a prática social que garante legitimidade para o uso da força pelo Estado, a melhor interpretação será aquela que articule coerentemente todos os seus elementos (regras, princípios, precedentes, etc.) a fim de que a decisão particular se ajuste ao valor que é a sua razão de ser. Dito de outro modo, a divergência é resolvida com a melhor justificação.

É nesse como se que reside o ideal normativo dworkiniano de integridade: uma concepção que entende o direito como uma estrutura de princípios coerentes de justiça, equidade, e devido processo; que entende que os juízes devem reforçar e guardar coerência com esses princípios, subjacentes à tradição jurídica, diante de novos casos que se apresentem - de modo que, precisamente por uma questão de equidade, as novas situações sejam julgadas de acordo com os mesmos padrões. É difícil? Talvez; mas o predicado dworkiniano fundamental rejeita a ideia de "not worth trying", de que não vale a pena tentar (WALDRON, 2012, pp. 180-181). 0 direito é como Dworkin diz que é? É difícil ser taxativo. Mas o mais importante é o como se.

Isso significa que o juiz responsável que adota o direito como integridade como sua concepção interpretativa - juiz que, na metáfora exemplificativa de Dworkin (1986, pp. 239-266), leva o nome de Hércules - deve, portanto, "testar sua interpretação acerca de qualquer parte da grande rede de estruturas e decisões políticas de sua comunidade perguntando se ela é capaz de fazer parte de uma teoria coerente que justifique essa rede como um todo"13 (DWORKIN, 1986, p. 245). Aquele que aceita o ideal interpretativo da integridade deve, então, decidir casos difíceis de modo a tentar encontrar a melhor interpretação construtiva da estrutura política e da prática jurídica da comunidade a partir de e em meio a um todo coerente de princípios de moralidade política (DWORKIN, 1986, p. 255); deve fazer dessa estrutura e dessa prática, como vimos, o melhor que elas podem ser.

À luz do direito como integridade, consagrado na analogia da prática como um romance em cadeia, as proposições jurídicas não são meras descrições mecânicas da história jurídica; daí não se segue que sejam dissociadas da história, da tradição institucional em que inseridas. Proposições de direito, tendo a integridade como princípio- 
ideal (normativo e explicativo) mais fundamental, são "interpretativas": combinam elementos de uma tradição institucional que contribuem para que, prospectivamente, o direito seja o melhor que ele pode ser. Direito como integridade é o direito que deve ser aquilo que ele já é interpretado construtivamente sob sua melhor luz. Cada novo capítulo, cada nova lei, cada nova decisão - cada acréscimo deve ser (institucionalmente) ajustado aos princípios daquilo que vem antes e que informam o que deve vir depois.

Integridade é uma concepção distinta da própria ideia de "legalidade". É uma leitura, afinal, que une o direito, no plano conceitual, à verdadeira noção de império da lei (DWORKIN, 2006, pp. 176-178). Daí a importância da analogia do romance em cadeia como ilustração que, mais do que simples analogia explicativa, consagra o ideal de integridade: decisões judiciais devem ser decisões de princípio; por trás disso, deve figurar, como premissa mais fundamental, a ideia de que o governo deve tratar todos os cidadãos como iguais.

É nesse sentido que, quando se trata de resolver desacordos - e na exata proporção em que esse é um papel inegável, inevitável do direito -, é muitas vezes preferível que essas decisões, finais, autoritativas, ocorram não no "battleground" da política, mas nas Cortes - que, tendo os juízes a responsabilidade política que lhes é exigida, tornam-se um "fórum de princípio", aptas a resolver de forma contramajoritária e ainda assim democrática; mais: democrática de verdade exatamente porque contramajoritária. Isso porque, afinal, os conflitos mais fundamentais devem, em algum lugar, ser tratados como questões de justiça. Nesse sentido, diz Dworkin: "não chamo a isso de religião ou profecia. Chamo a isso de direito" 14 (DWORKIN, 1985, p. 71). Trata-se, nas palavras do próprio autor, de um argumento "teorético" e, sobretudo, "institucional" (DWORKIN, 1985, p. 28), que está - como não poderia ser diferente intimamente ligado à sua concepção interpretativa sobre o fenômeno jurídico tal como ele é.

\section{COERÊNCIA E INTEGRIDADE NO DIREITO BRASILEIRO}


Se a força argumentativa em Dworkin já não fosse suficiente para clarificar a necessidade de que suas ideias sejam levadas a sério por aqui, basta lembrar que, no Brasil, coerência e integridade são exigência legislativa. O Código de Processo Civil, em 2015, consagrou — com os incentivos da Crítica Hermenêutica do Direito (STRECK, 2016) —, no art. 926, a exigência de respeito a esses princípios eminente e claramente dworkinianos. ( 0 art. 926 é potencializado pelo art. 10 em suas "garantias de influência e não surpresa”, estabelecendo um controle público do perigoso poder cautelar do juiz. A coerência e a integridade são, assim, os vetores principiológicos do CPC. Em qualquer decisão judicial, a fundamentação deve respeitar a coerência e a integridade.)

Na medida em que o CPC é taxativo, ele obriga; portanto, devemos levar o texto jurídico a sério. Assim, a partir da aprovação do CPC/2015, toda decisão em que se constata que não foram obedecidas a coerência e a integridade é recorrível. Ou seja, uma decisão incoerente e/ou não íntegra será errada e, portanto, digna de reforma. 0 julgador que profere uma decisão incoerente ou afastada da integridade comete um equívoco jurídico. Compreender o ideal de integridade, por consequência, é algo necessário para uma correta aplicação da lei no direito brasileiro.

Coerência e integridade. Será a integridade apenas uma questão de coerência (ou seja, respeitar os capítulos anteriores/decidir casos semelhantes da mesma maneira) sob um nome mais grandioso? Isso dependerá, por óbvio, daquilo que efetivamente entendemos por coerência ou casos semelhantes. Se uma instituição política só é coerente quando repete suas próprias decisões anteriores o mais fiel ou precisamente possível, então a integridade não é coerência: a integridade exige, vimos, que as normas públicas da comunidade sejam criadas e vistas, na medida do possível, de modo a expressar um sistema único e coerente de justiça e direito a um tratamento equânime na correta proporção: fairness.

\section{A QUESTÃO DO PRECEDENTE}

Isso não é mera abstração; tem repercussões diretas na prática. Analisemos isso, primeiramente, à luz da questão do precedente judicial: 
precedentes (também no Brasil) são, afinal, vinculantes? Há quem diga que sim (MELLO, BARROSO, 2016; MITIDIERO, 2013, 2016; MARINONI, 2010).

0 ponto é que, por vezes, aceitar a ideia de integridade frisamos, exigência legislativa - é justamente o que exige que um juiz afaste-se da estreita linha das decisões anteriores, em busca não de uma jurisprudência mecânica, mas de fidelidade aos princípios mais fundamentais da comunidade política como um todo (STRECK, 2019). A integridade, interpretada a partir do romance em cadeia, é uma norma muito mais dinâmica e radical do que uma leitura rasa dá a entender: ela incentiva um juiz a ser mais abrangente e imaginativo em sua busca de coerência com o princípio fundamental, respeitando passado, presente e futuro. Nem (apenas) descrição, nem (somente) valoração. Um equilíbrio entre esses dois elementos (DWORKIN, 1985, p. 147).

Para Dworkin, portanto, as decisões pretéritas não devem ser entendidas como pronunciamentos a serem convencionalmente aplicados; em vez disso, o juiz, diante de um novo caso, deve decidir a partir dos princípios que subjazem às decisões precedentes, combinando história institucional e moralidade política. (STRECK, 2017b, p. 92). 0 respeito ao elemento (genuinamente) vinculante na ratio decidendi, no stare decisis como tal, está na aplicação dos princípios subjacentes à decisão do tribunal que a tiver proferido. De acordo com essa interpretação, o precedente, em relação ao contexto factual do caso que lhe serviu de origem, não apenas exibe como serve de suporte a princípios jurídicos que, em razão de seu papel no ordenamento, podem (e devem) ter relevância na decisão de casos futuros. Os tribunais subsequentes olham para os precedentes (no sentido lato, de decisões pretéritas) e, quando da identificação do que constitui a ratio, verificam se eles representam princípios suficiente e adequadamente justificatórios quanto à decisão a ser tomada no caso que estiver em questão (PERRY, 1987, pp. 215-257).

Decisões judicias pretéritas, assim, exercem uma força gravitacional pormeio e em razão da integridade: no direito, o genuíno respeito à tradição e à histórica institucional exige não uma adesão cega e mecanicizada àquilo que foi anteriormente decidido; exige, fundamentalmente, uma abordagem do precedente à luz dos melhores argumentos de princípio que o sustentam, mostrando que o direito trata os cidadãos de forma justa 
e equânime naquilo que o fenômeno jurídico tem de mais fundamental (GUEST, 2013, p. 89). Coerência e integridade manifestam-se, pois, como elementos da igualdade. No caso específico da decisão judicial, isso significa que os diversos casos serão julgados não de forma idêntica, mas com igual consideração. Esse é o ponto.

Um sistema jurídico que respeita as exigências do ideal de coerência e integridade dispensa os precedentes interpretados como teses gerais, abstratas, vinculantes, proferidas pelos tribunais. Primeiro, porque respeitar a integridade tal como articulada por Dworkin é o que já confere estabilidade decisória e segurança jurídica ao sistema por si só. Afinal, respeitar ou agir de forma coerente e íntegra quer dizer que o ato de aplicar a lei traz responsabilidade política. Um sistema jurídico que tem na coerência e integridade o seu vetor de racionalidade nem precisaria ter mecanismos formais de vinculação jurisprudencial. Se o Judiciário julga por princípio, o corolário é a manutenção da coerência e, consequentemente, da integridade.

Segundo, porque uma vinculação cega, rígida, mecânica pode, como vimos, contrariar o próprio ideal de integridade. É óbvio que um sistema jurídico deve garantir um mínimo grau de previsibilidade aos jurisdicionados. Mas não existe maior segurança jurídica que a certeza de que a atividade decisória será exercida num contexto de respeito aos princípios da tradição jurídico-institucional. Não há melhor maneira de respeitar a lei do que interpretá-la à (melhor) luz dos princípios que lhe dão forma. Não há vinculação mais autêntica que respeitar as demandas e as exigências a que deve atender aquele que respeita o ideal de coerência e a integridade do direito. Guardar coerência com o direito exige respeito aos seus princípios próprios, e não uma vinculação mecanicista às respostas pretensamente vinculantes que surgem de cima pra baixo.

O que se quer dizer, basicamente, é que (i): o ideal de coerência e integridade, quando respeitado, já garante tudo que se quer quando se pede segurança jurídica e que (ii) teses mecânicas, rígidas, tornam um sistema hermético e, atreladas a um paradigma já superado, podem contrariar o próprio ideal de integridade. Apenas para fins de ilustração: um exemplo, concreto, vem da ADI 2.591, em que o STF decidiu, corretamente, que o Código do Consumidor passaria a ser igualmente 
aplicado às instituições financeiras, acabando com significativa divergência jurisprudencial. Até seria coerente continuar a decidir pela não aplicação do CDC aos contratos bancários. Ou seja, pode-se ser coerente no erro. Mas não haveria integridade. Afinal, uma teoria do precedente que condene juízes e Tribunais a repetir seus erros "não se ajusta nem justifica a prática jurídica"15 (HERSHOVITZ, 2012, p. 103).

\section{PRINCÍPIOS AUTÊNTICOS (E INAUTÊNTICOS)}

Isso não está refletido apenas na questão do precedente. Na exata medida em que representa a ideia de legalidade, de império da lei, o direito como um romance em cadeia pode servir de ideal normativo a uma série de outros problemas enfrentados pelo direito brasileiro.

Que dizer, em mais um lamentável exemplo, de uma série de (supostos) "princípios" sustentados por juízes e tribunais no Brasil? A partir das (mais que) legítimas considerações de Dworkin, uma série de argumentos retóricos, ad hoc, sem qualquer grau de institucionalidade, são invocados de forma a justificar qualquer decisão. Parcela da comunidade jurídica respondeu à pergunta que sempre perturbou o direito ("o que fazer com a moral?") com a seguinte resposta: "Princípios são valores e trazem a moral para dentro do direito". Isso fragilizou absolutamente o necessário grau de autonomia que o direito exige preservar em uma democracia autêntica.

Fosse naturalizado o ideal de integridade, seria peremptoriamente rejeitada pelos juristas uma tese ou postura que permite que um standard qualquer tenha a possibilidade de balizar o direito aprovado democraticamente pelo Parlamento. Pois não foi isso que aconteceu e o que vem ocorrendo - exatamente porque não se naturalizou o ideal de integridade. 0 direito foi inundado por uma produção de standards valorativos, álibis teóricos pelos quais se pode dizer qualquer coisa sobre a interpretação da lei. Ora, os princípios - genuínos, autênticos - são jurídicos precisamente porque, já a priori, fazem parte do direito; são padrões que devem ser observados por uma questão de moralidade política (DWORKIN, 1978, p. 22), institucionalizada, e, por isso, conduzem a argumentação e o raciocínio jurídico. 
No Brasil, ao contrário, "princípios"16 acabam sendo invocados como meros argumentos retóricos - e, portanto, levam erroneamente o nome de princípio; são jargões que carecem tanto de institucionalidade quanto de sentido, porque, invocados a posteriori, apontam não a algo que faça parte do direito, mas tão somente àquilo que o julgador tinha em mente quando decidiu o caso em questão (na maior parte das vezes, de forma discricionária; afinal, não haveria qualquer necessidade de recorrência a um princípio ad hoc em caso de uma decisão fundamentada em algo que não o juízo do intérprete que a profere). "Princípio da afetividade"; "princípio da instrumentalidade processual"; o célebre "princípio da colegialidade" (STRECK, 2017b, pp. 559-564). Que tipo de "princípios" seriam esses, que (i) nada vinculam e (ii) não carregam, nem sequer reivindicam qualquer relação com fundamentos jurídicos devidamente institucionalizados?

Não é só isso. A questão é muito maior. O ponto fundamental, claro, reside para muito além disso.

\section{CONSIDERAÇÕES FINAIS: INTEGRIDADE E DECISÃO JUDICIAL}

Princípios autênticos e inautênticos, interpretação correta sobre a doutrina do precedente... seja o que for. Esses são reflexos de uma questão muito mais complexa, importante e interessante que transcende suas manifestações tomadas isoladamente. 0 ponto mesmo, fundamental, é que, com a sacralização da coerência e integridade na lei positiva, o direito brasileiro acabou por consagrar (na via legislativa) aquilo que, corretamente compreendida, a própria ideia de democracia já exige: a ideia de que

[...] sentença e acórdãos são atos de decisão e não de escolha. São atos de poder em nome do Estado. [...] Respostas de escolha são respostas parciais; respostas de decisão são respostas totais, nas quais entra em jogo a existência inteira. [...] [H]á uma diferença entre o decidir, que é um ato de responsabilidade política e o escolher, que é um ato de razão prática. 0 primeiro é um ato estatal; o segundo, da esfera do cotidiano, de agir estratégico.

É por isso, afinal, que 
[...] a democracia sempre corre perigo se a aplicação do Direito pelos juízes e Tribunais é feita sem uma adequada teoria da decisão judicial, enfim, de uma criteriologia e, finalmente, sem mirar em uma resposta correta. (STRECK, 2017a, p. 253)

Respostas corretas - ou adequadas (STRECK, 2017a, p. 251) em direito. Essa é a exigência da integridade - repetimos, consagrada na lei positiva no Brasil. E é isso, fundamentalmente, que a analogia do romance em cadeia pretende descrever e prescrever: combinando história institucional e facticidade, institucionalizando princípios autênticos de moralidade política consagrados na tradição da democracia liberal em que inserido o direito, o juiz decide. Juiz não escolhe; não quando adota o ideal de integridade subjacente à tarefa jurídica de fazer do romance que é o direito o melhor que ele pode ser. A obrigação não é (só) de resultado: é também de meio.

Daí, então, a importância do romance em cadeia como metáfora explicativa e constitutiva do direito - daquilo que ele deve ser à luz da melhor intepretação daquilo que já é.

Não se trata de mera metáfora desimportante. É isso que, no dizer de Waldron que abre este ensaio, ela tem sido mal compreendida: a história da literatura jurídica não foi capaz de ver na analogia do romance em cadeia que ela ilustra a própria ideia de integridade (que, por sua vez, ilustra a própria ideia de império da lei): cada juiz que decide está posicionado em determinado momento de uma história institucional; história que lhe antecede, que seguirá depois dele, e, principalmente, na qual ele tem interferência direta. É por isso que deve interpretar o que aconteceu e dar-lhe continuidade da melhor maneira possível.

Cada novo capítulo deve ser escrito e acrescentado de forma a se articular ao todo coerente do livro, mantendo uma consistência com a narrativa que lhe constitui à luz da ideia de que o romance deve fazer sentido como se escrito por um só. Cada tomada de decisão deve articularse ao todo coerente do direito, mantendo uma consistência com os princípios constitutivos da comunidade ajustados e interpretados à luz da história jurídico-institucional. 
A decisão judicial como um capítulo novo num romance escrito por mais de um autor. Que antecede e seguirá para além daquele à frente da máquina de escrever. Um novo capítulo como a decisão judicial no direito. Que antecede e seguirá para além daquele que tem a responsabilidade política de decidir.

É assim, então, que Dworkin estabelece a possibilidade e a necessidade de decisões judiciais corretas através da coerência e integridade normativas. Em síntese: a resposta correta (adequada) tem um grau de abrangência que evita decisões ad hoc. Decidir, afinal, é agir com responsabilidade política. Responsabilidade de meio e de resultado na interpretação construtiva (e construção interpretativa) da resposta correta a partir da melhor interpretação possível do material jurídico básico - leis, códigos, precedentes, etc. - e dos princípios que conformam esse empreendimento coletivo, esse romance em cadeia, a que chamamos direito.

É uma questão de postura, pois, de atitude, diante de um problema jurídico (e não sómoral e não só político e não só econômico). Responsabilidade de aplicar o direito corretamente. Por uma questão, afinal, de... princípio (DWORKIN, 1985). Uma questão de levar os direitos a sério (DWORKIN, 1978), de levar o império do direito a sério (DWORKIN, 1986).

Por uma questão de coerência e integridade. Por uma questão, afinal, de império da lei.

\section{NOTAS}

1 "He has now for many decades been enormously cited in legal, political, philosophical and economics books and journals, and serious writers who disagree or agree with him are certainly united in thinking his ideas are of great significance."

2 Para os fins deste artigo, não traçamos qualquer diferença significativa entre "moral" e "ética". Usá-los-emos intercambiavelmente.

3 "[O]ne of the most complex, interesting, and original conceptions in legal philosophy."

4 "Jurists have found this an attractive metaphor, and they seem happy to consider its application without troubling themselves too much about the underlying argument. But why is the law like a chain novel? Why isn't it like collection of short stories by William Trevor or Flannery O'Connor? The question is never broached by those who make use of Dworkin's image."

5 Grifos nossos, tradução livre. "[L]egal reasoning is an exercise in constructive interpretation. [...] [O] ur law consists in the best justification of our legal practices as a whole, [...] it consists in the narrative story that makes of these practices the best they can be".

6 "[T] he interpreter settles on some general justification for the main elements of the practice identified at the preinterpretive stage". 
7 “[The interpreter] adjusts his sense of what the practice 'really' requires so as better to serve the justification he accepts at the interpretive stage".

8 "[R] ights and responsibilities flow from past decisions and so count as legal, not just when they are explicit in these decisions but also when they follow from the principles of personal and political morality the explicit decisions presuppose by way of justification".

9 "Law as integrity denies that statements of law are either the backward-looking factual reports of conventionalism or the forward-looking instrumental programs of legal pragmatism. It insists that legal claims are interpretive judgments and therefore combine backward and forward-looking elements; they interpret contemporary legal practice seen as an unfolding political narrative. So law as integrity rejects as unhelpful the ancient question whether judges find or invent law; we understand legal reasoning, it suggests, only by seeing the sense in which they do both and neither".

100 termo é frequentemente traduzido como "funcionários". Na literatura jurídica anglo-saxônica, é utilizado de modo a representar todos aqueles que compõem a prática político-judiciária, a produção e aplicação legislativa, o reforço no cumprimento das leis, etc.

11 "Each novelist aims to make a single novel of the material he has been given, what he adds to it, and (so far as he can control this) what his successors will want or be able to add. He must try to make this the best novel it can be can be construed as the work of a single author rather than, as is the fact, the product of many different hands."

12 " $[A] s$ if the rights and policies political institutions promote and protect all stem from a coherent set of principles, a set of principles that can be endorsed by a single moral agent."

13 Law as integrity [...] requires a judge to test his interpretation of any part of the great network of political structures and decisions of his community by asking whether it could form part of a coherent theory justifying the network as a whole".

14 Grifos nossos, em trechos livremente traduzidos de "[w]e have an institution that calls some issues from the battleground of power politics to the forum of principle. It holds out the promise that the deepest, most fundamental conflicts between individual and society will once, someplace, finally, become questions of justice. I do not call that religion or prophecy. I call it law."

15 "The view that stare decisis condemns courts to repeat their mistakes neither fits nor justifies our legal practice."

16 Nesse sentido, ver o verbete "Pamprincipiologismo" em STRECK, 2017a.

\section{REFERÊNCIAS}

DWORKIN, Ronald. A Matter of Principle. Cambridge: The Belknapp Press, 1985.

DWORKIN, Ronald. Freedom's Law: The Moral Reading of the American Constitution. Oxford: Oxford University Press, 2005.

DWORKIN, Ronald. Justice for Hedgehogs. Cambridge: Belknap Press, 2011.

DWORKIN, Ronald. Justice in Robes. Cambridge: The Belknapp Press, 2006.

DWORKIN, Ronald. Law's Empire. Cambridge: The Belknapp Press, 1986.

DWORKIN, Ronald. Taking Rights Seriously. Cambridge: Harvard University

Press, 1978.

GUEST, Stephen. Ronald Dworkin. 3. ed. Stanford: Stanford University Press, 2013. 
HERSHOVITZ, Scott. Integrity and Stare Decisis. In: HERSHOVITZ, Scott (ed). Exploring Law's Empire: The Jurisprudence of Ronald Dworkin. Oxford: Oxford University Press, 2012, pp. 103-118.

MARINONI, Luiz Guilherme. Precedentes Obrigatórios. São Paulo: Revista dos Tribunais, 2010.

MARMOR, Andrei. Integrity in Law's Empire. Balzan Conference: Dworkin's LateWork, Nova York, New York University School of Law, ago. 2019. Disponível em: <https:// www.law.nyu.edu/centers/lawphilosophy/balzan>. Acesso em 09 set. 2019.

MELLO, Patrícia Perrone Campos; BARROSO, Luís Roberto. Trabalhando com uma nova lógica: a ascensão dos precedentes no Direito brasileiro. In: Revista da AGU, v. 15, n. 3. Brasília: Fórum, jul./set. 2016, pp. 09-52.

MITIDIERO, Daniel. Cortes Superiores e Cortes Supremas: do Controle à Interpretação, da Jurisprudência ao Precedente. São Paulo: Revista dos Tribunais, 2013.

MITIDIERO, Daniel. Precedentes: da persuasão à vinculação. São Paulo: Revista dos Tribunais, 2016.

PERRY, Stephen R. Judicial obligation, Precedent, and the Common Law. Oxford Journal of Legal Studies, Oxford, vol. 07, n. 02, jul. 1987, pp. 215-257. Disponível em: <https://doi.org/10.1093/ojls/7.2.215>. Acesso em 09 set. 2019.

STRECK, Lenio Luiz. Dicionário de Hermenêutica: Quarenta Temas Fundamentais da Teoria do Direito à Luz da Crítica Hermenêutica do Direito. Belo Horizonte: Casa do Direito, 2017a.

STRECK, Lenio Luiz. 0 que é isto - a exigência de coerência e integridade No novo Código de Processo Civil. In: STRECK, Lenio Luiz; ARRUDA ALVIM, Eduardo; SALOMÃO, George Leite. Hermenêutica e Jurisprudência no Novo Código de Processo Civil: coerência e integridade. São Paulo: Saraiva, 2016.

STRECK, Lenio Luiz. Precedentes Judiciais e Hermenêutica: O Sentido da Vinculação no CPC/2015. 2. ${ }^{\text {a }}$ edição, revista e ampliada. Salvador: Juspodivm, 2019.

STRECK, Lenio Luiz. Verdade e Consenso: Constituição, Hermenêutica e Teorias Discursivas. 6. ${ }^{\mathrm{a}}$ edição, revista, ampliada e modificada. São Paulo: Saraiva, 2017b.

WALDRON, Jeremy. Did Dworkin Ever Answer the Crits? In: HERSHOVITZ, Scott (ed). Exploring Law's Empire: The Jurisprudence of Ronald Dworkin. Oxford: Oxford University Press, 2012, pp. 155-182. 
WALDRON, Jeremy. The Rise and Decline of Integrity. Balzan Conference: Dworkin's Late Work, Nova York, New York University School of Law, ago. 2019. Disponível em: <https://www.law.nyu.edu/centers/lawphilosophy/balzan>. Acesso em 09 set. 2019.

Recebido em: 12-9-2019

Aprovado em: 09-12-2019

Autores convidados

\section{Lenio Luiz Streck}

Pós-doutor pela Universidade de Lisboa, doutor e mestre em Direito pela Universidade Federal de Santa Catarina. Professor titular do Programa de Pós-Graduação em Direito (Mestrado e Doutorado) da UNISINOS, na área de concentração em Direito Público. Professor permanente da UNESA-RJ, de ROMATRE (Scuola Dottorale Tulio Scarelli), da Faculdade de Direito da Universidade de Coimbra - FDUC (Acordo Internacional Capes-Grices) e da Faculdade de Direito da Universidade de Lisboa. Membro catedrático da Academia Brasileira de Direito Constitucional - ABDConst. Presidente de Honra do Instituto de Hermenêutica Jurídica - IHJ (RS-MG). Membro da comissão permanente de Direito Constitucional do Instituto dos Advogados Brasileiros - IAB, do Observatório da Jurisdição Constitucional do Instituto Brasiliense de Direito Público - IDP, da Revista Direitos Fundamentais e Justiça, da Revista Novos Estudos Jurídicos, entre outros. Coordenador do DASEIN. Núcleo de Estudos Hermenêuticos. E-mail: lenios@globomail.com

\section{Gilberto Morbach Júnior}

Mestre em Direito Público (summa cum laude), como bolsista do Conselho Nacional de Desenvolvimento Científico e Tecnológico (CNPq), pela Universidade do Vale do Rio dos Sinos (Unisinos). Bacharel em Direito pela Universidade Feevale. Membro e assistente do coordenador, Prof. Dr. Lenio Luiz Streck, do Dasein - Núcleo de Estudos Hermenêuticos; também membro da Aristotelian Society for the Systematic Study of Philosophy (Aristotelian Society) e da ABDPro - Associação Brasileira de Direito Processual. Advogado. E-mail: gilbertomorbach@gmail.com

Universidade do Vale do Rio dos Sinos, Centro de Ciências Jurídicas, Programa de Pós Graduação Em Direito.

Av. Unisinos, 950 - Cristo Rei, São Leopoldo - RS, 93022-750 